\title{
Erosão em sulcos e entressulcos em razão do formato de parcela em Argissolo Vermelho-Amarelo arênico(1)
}

\author{
José Miguel Reichert(2), Marcos José Schäfer ${ }^{(3)}$ \\ Flávio Luiz Folleto Eltz ${ }^{(2)}$ e Lloyd Darrell Norton ${ }^{(4)}$
}

\begin{abstract}
Resumo - O objetivo deste trabalho foi avaliar o efeito de parcelas de erosão com seções transversais da superfície do solo retangular (STR) e triangular (STT) na perda de solo e água e na erodibilidade, em sulcos e entressulcos. O experimento foi conduzido em 1998, em um Argissolo Vermelho-Amarelo distrófico arênico, preparado convencionalmente. As dimensões das parcelas de entressulcos foram de $0,50 \mathrm{~m}$ por $0,75 \mathrm{~m}$; nos sulcos com STR, as dimensões foram de $0,20 \mathrm{~m}$ por $5,90 \mathrm{~m}$, e nos de STT, de $0,50 \mathrm{~m}$ por $5,90 \mathrm{~m}$. Utilizou-se chuva simulada constante de $65 \mathrm{~mm} \mathrm{~h}^{-1}$ nos entressulcos, durante 90 minutos. Nos sulcos, após pré-umedecimento do solo, foram aplicadas cinco vazões extras crescentes de $0,0002 \mathrm{~m}^{3} \mathrm{~s}^{-1}$ até $0,0010 \mathrm{~m}^{3} \mathrm{~s}^{-1}$. A desagregação nos entressulcos Di $\left(2,09.10^{-4} \mathrm{~kg} \mathrm{~m}^{-2} \mathrm{~s}^{-1}\right.$ nas STR e $3,35.10^{-4} \mathrm{~kg} \mathrm{~m}^{-2} \mathrm{~s}^{-1}$ nas STT), a erodibilidade nos entressulcos $\mathrm{Ki}\left(1,77.10^{6} \mathrm{~kg} \mathrm{~s} \mathrm{~m}^{-4}\right.$ nas STR e $2,00.10^{6} \mathrm{~kg} \mathrm{~s} \mathrm{~m}^{-4}$ nas STT), a erodibilidade em sulcos $\operatorname{Kr}\left(0,0110 \mathrm{~kg} \mathrm{~N}^{-1} \mathrm{~s}^{-1}\right.$ nas STR e $0,0074 \mathrm{~kg} \mathrm{~N}^{-1} \mathrm{~s}^{-1}$ na STT) e a tensão crítica de cisalhamento $\tau$ c $\left(2,61 \mathrm{~N} \mathrm{~m}^{-2}\right.$ na STR e $2,00 \mathrm{~N} \mathrm{~m}^{-2}$ na STT) não foram estatisticamente diferentes nos dois formatos de seção transversal, e podem ser determinados usandose qualquer um dos formatos de parcelas em solos de textura superficial arenosa.
\end{abstract}

Termos para indexação: solos arenosos, erosão hídrica, degradação do solo.

\section{Interrill and rill erosion as affected by plot configuration on a sandy loam Hapludalf soil}

\begin{abstract}
The objective of this study was to compare rill and interrill erodibility and critical shear stress, for two configurations of soil surface: rectangular (RCS) and triangular (TCS) cross-sections. The experiment was done in 1998 on a conventionally tilled Hapludalf with a sandy loam soil surface texture. The interrill plot dimensions were 0.50 by $0.75 \mathrm{~m}$, while for rill, the dimensions were 0.20 by $5.90 \mathrm{~m}$ for RCS, and 0.50 by $5.90 \mathrm{~m}$ for TCS. Constant simulated rain of $65 \mathrm{~mm} \mathrm{~h}^{-1}$ was applied on the interrill plots for 90 minutes, whereas for the rills, besides rain to prewet the soil, five extra inflows of $0.0002 \mathrm{~m}^{3} \mathrm{~s}^{-1}$ up to $0.0010 \mathrm{~m}^{3} \mathrm{~s}^{-1}$ were applied. The interrill detachment rate $\mathrm{Di}\left(2.09 \times 10^{-4} \mathrm{~kg} \mathrm{~m}^{-2} \mathrm{~s}^{-1}\right.$ for RCS and $3.35 \times 10^{-4} \mathrm{~kg} \mathrm{~m}^{-2} \mathrm{~s}^{-1}$ for TCS), interrill erodibility $\mathrm{Ki}\left(1.77 \times 10^{6} \mathrm{~kg} \mathrm{~s} \mathrm{~m}^{-4}\right.$ for RCS and $2.00 \times 10^{6} \mathrm{~kg} \mathrm{~s} \mathrm{~m}^{-4}$ for TCS), rill erodibility $\operatorname{Kr}\left(0.0110 \mathrm{~kg} \mathrm{~N}^{-1} \mathrm{~s}^{-1}\right.$ for RCS e $0.0074 \mathrm{~kg} \mathrm{~N}^{-1} \mathrm{~s}^{-1}$ for TCS), and critical shear stress $\tau \mathrm{c}\left(2.61 \mathrm{~N} \mathrm{~m}^{-2}\right.$ for RCS e $2.00 \mathrm{~N} \mathrm{~m}^{-2}$ for TCS) were not statistically different for the two cross-sections, and can be determined on any of the plot configuration for sandy loam soils.
\end{abstract}

Index terms: sandy soils, water erosion, soil deterioration.

\footnotetext{
(1)Aceito para publicação em 12 de setembro de 2000 . Extraído da Dissertação de Mestrado apresentada pelo segundo autor à Universidade Federal de Santa Maria (UFSM), Santa Maria, RS. Parcialmente financiado pela FAPERGS e pelo Pronex-CNPq/FINEP.

(2)UFSM, Dep. de Solos, Campus Universitário, CEP 97105-900 Santa Maria, RS. Bolsista do CNPq. E-mail: reichert@ccr.ufsm.br, feltz@ccr.ufsm.br

${ }^{(3)}$ Rua 5 de Março, 83, CEP 97110-000 Santa Maria, RS.

${ }^{(4)}$ Purdue University, USDA-NSERL, Soils Building, 47905 West Lafayette, IN, USA. E-mail: norton@purdue.edu
}

\section{Introdução}

A determinação da erodibilidade do solo em estudos da erosão nos sulcos e nos entressulcos, usando-se a metodologia do modelo WEPP (Water Erosion Prediction Project), prevê três períodos de testes (Elliot et al., 1989). No primeiro período, utilizando-se apenas chuva, é avaliada a erodibilidade em entressulcos (Ki). No segundo período, com a aplicação de vazões extras na extremidade superior do sulco juntamente com a chuva simulada, determi- 
na-se a erosão em sulcos, e, com a contribuição de sedimentos oriundos da região, em entressulcos. No terceiro período, são aplicadas somente vazões extras, obtendo-se os dados para a determinação da erodibilidade em sulcos $(\mathrm{Kr})$ e a tensão cisalhante crítica $(\tau c)$ sem a contribuição de sedimentos provindos da área em entressulcos.

Nesse procedimento, usando as vazões extras no mesmo sulco, cada vazão permanece no sulco somente o tempo necessário para estabilizar o escoamento e para realizar as determinações (Elliot et al., 1989), a fim de evitar que o escoamento atinja a camada não-arada (Franti et al., 1985; Cassol \& Lima, 1998), o que inviabilizaria a determinação da erodibilidade em sulcos na condição de máxima suscetibilidade à erosão do solo.

As vazões extras são aplicadas no segundo e no terceiro períodos, todas no mesmo sulco, seqüenciadas das menores para as maiores vazões. Entretanto, essas etapas foram simplificadas por outros autores. West et al. (1992), Brown \& Norton (1994) e Cassol \& Lima (1998) umedeceram o solo, e, posteriormente, aplicaram-se as vazões extras sem chuva, enquanto Braida \& Cassol (1996a, 1996b) e Giasson \& Cassol (1996) usaram um sulco para cada vazão.

$\mathrm{Na}$ determinação da erodibilidade nos entressulcos e nos sulcos, o procedimento experimental recomendado é o de preparar o solo de forma convencional, e instalar uma parcela com declividade lateral orientada para o centro; essa parcela deve ser mantida descoberta durante os ensaios e ter seção transversal triangular (STT) (Elliot et al., 1989). Entretanto, em condições especiais, como em cultivos conservacionistas, nos quais a superfície do solo não pode ser revolvida, sob pena de interferir no tratamento, a conformação triangular da seção transversal desejada nem sempre é possível de se obter, exceto em preparo em camalhão.

No estudo da erosão nos entressulcos e nos sulcos em solo com preparo em camalhões ("ridgetillage"), Norton \& Brown (1992) e Brown \& Norton (1994) usaram parcelas experimentais com inclinação lateral além da inclinação natural do terreno (STT). Entretanto, King (1992) estudou a erosão em sulcos, utilizando chapas metálicas para delimitar os sulcos artificiais, sem pré-formação dos mesmos, configu- rando uma seção transversal plana ou retangular (STR).

No Rio Grande do Sul, esses dois tipos de parcelas (STT e STR) vêm sendo utilizados no estudo da erosão nos entressulcos e nos sulcos. Para estudar a erosão nos sulcos, Giasson \& Cassol (1996) e Braida \& Cassol (1996b, 1999) usaram sulcos pré-formados e com seção transversal triangular (STT). Para erosão nos entressulcos, Braida \& Cassol (1996b, 1999) utilizaram unidades experimentais planas, delimitadas por chapas metálicas, apresentando apenas a declividade natural do terreno (STR), enquanto Rockenbach (1992) estudou a erosão em entressulcos, utilizando, além da declividade natural do terreno, uma declividade lateral de 9\% (STT), das bordas para o centro. Entretanto, não se sabe se o formato da seção transversal afeta os resultados de escoamento e erosão, alternando as perdas de solo e água, e os parâmetros $\mathrm{Ki}, \mathrm{Kr}$ e $\tau \mathrm{c}$.

A literatura apresenta resultados da comparação de formatos de seção transversal apenas em relação à erosão nos entressulcos, mostrando maior infiltração de água e erosão do solo, porém erodibilidade nos entressulcos, em parcela com seção transversal plana similar à triangular (Liebenow et al., 1990).

O objetivo deste trabalho foi avaliar o efeito de parcelas de erosão com seções transversais da superfície do solo retangular e triangular na perda de solo e água e na erodibilidade, em sulcos e entressulcos.

\section{Material e Métodos}

\section{Tratamentos e determinações}

O experimento foi conduzido em 1998, na área experimental do Departamento de Solos da Universidade Federal de Santa Maria (UFSM), localizada no Município de Santa Maria, RS. O solo estudado foi um Argissolo Vermelho-Amarelo distrófico arênico (Embrapa, 1999), da unidade de mapeamento São Pedro, desenvolvido a partir de arenitos e com argila de atividade baixa. O solo após o preparo apresentava $25 \mathrm{~g} \mathrm{~kg}^{-1}$ de matéria orgânica, $0,99 \mathrm{Mg} \mathrm{m}^{-3}$ de densidade do solo, $190 \mathrm{~g} \mathrm{~kg}^{-1}$ de argila, $24 \mathrm{~g} \mathrm{~kg}^{-1}$ de silte, e $57 \mathrm{~g} \mathrm{~kg}^{-1}$ de areia e $60 \mathrm{~cm} \mathrm{~cm}^{3}$ de porosidade total.

O delineamento experimental adotado foi o inteiramente casualizado, com seis repetições. Os tratamentos consistiram de parcelas de erosão com superfície plana sem 
declividade lateral construída, em seções transversais retangulares (STR), e com superfície inclinada lateralmente para o centro, além da declividade natural do terreno, em seções transversais triangulares (STT).

No tratamento STR, as dimensões das parcelas foram: nos entressulcos, com STR: $0,50 \times 0,75 \mathrm{~m}$, sendo que a maior dimensão ficou no sentido do declive; nos sulcos, com STR: $0,20 \times 5,90 \mathrm{~m}$. No tratamento STT, as dimensões das parcelas foram: nos entressulcos: $0,50 \mathrm{~m}$ de largura, $0,75 \mathrm{~m}$ de comprimento e $0,05 \mathrm{~m}$ de profundidade na porção central ( $20 \%$ de declividade lateral); nos sulcos: 0,50 m de largura, 5,90 m de comprimento e $0,05 \mathrm{~m}$ de profundidade na porção central $(20 \%$ de declividade lateral).

A área experimental vinha sendo utilizada para produção de grãos e possuía uma história de seis anos consecutivos no sistema de plantio direto. Para a instalação do experimento foi retirada a palha da superfície do solo. Os dois tratamentos foram preparados com uma lavração com arado de discos, a uma profundidade média de $20 \mathrm{~cm}$, $\mathrm{e}$, no dia seguinte, duas gradagens com grade niveladora. Posteriormente, o solo permaneceu sem cobertura e isento de invasoras durante dois meses.

Antes da chuva simulada, o solo foi novamente preparado manualmente, com o auxílio de uma pá de corte, a uma profundidade de $0,20 \mathrm{~m}$, e um rastelo, para destorroamento e nivelamento. No tratamento STT, o sulco foi construído com um sulcador para formar a inclinação lateral para o centro.

Para aplicar a chuva na área em entressulcos, foi usado um simulador estacionário de bicos múltiplos e oscilantes (Norton \& Brown, 1992), instalado a uma altura de $2,45 \mathrm{~m}$ da superfície do solo e com a pressão de saída da água nos bicos mantida em 41,4 kPa. A chuva, de $65 \mathrm{~mm} \mathrm{~h}^{-1}$, foi aplicada durante 90 minutos, para realizar as coletas propostas.

O escoamento foi coletado em recipientes, a cada 5 minutos, por meio da calha colocada na porção inferior da parcela de erosão. O tempo necessário para o enchimento do recipiente foi cronometrado e anotado, para cálculos posteriores. A viscosidade e a densidade da água foram corrigidas em razão da temperatura da água usada em cada ensaio.

As amostras coletadas do escoamento foram levadas ao laboratório, onde os potes com solo e água foram pesados. Após adição de floculante, os potes permaneceram em repouso até o dia seguinte, quando se sifonou o máximo possível da água. Posteriormente, os potes foram levados para estufa a uma temperatura de 60 a $65^{\circ} \mathrm{C}$ até peso constante, para posterior pesagem.
A resistência do solo ao cisalhamento $(\tau s)$ foi determinada com o auxílio de um aparelho denominado Torvane (Holtz \& Kovacs, 1981), imediatamente após o término da chuva, com 15 medições aleatórias em cada parcela.

Em sulcos, uma chuva de $65 \mathrm{~mm} \mathrm{~h}^{-1}$ foi aplicada durante o tempo necessário para levar o solo a uma infiltração aproximadamente constante. Imediatamente após a chuva, foram adicionadas vazões de $0,0002 \mathrm{~m}^{3} \mathrm{~s}^{-1} ; 0,0004 \mathrm{~m}^{3} \mathrm{~s}^{-1}$; $0,0006 \mathrm{~m}^{3} \mathrm{~s}^{-1} ; 0,0008 \mathrm{~m}^{3} \mathrm{~s}^{-1}$ e $0,0010 \mathrm{~m}^{3} \mathrm{~s}^{-1}$, aferidas com um rotâmetro. As coletas do escoamento foram realizadas com o auxílio de uma calha colocada no segmento final do sulco. Foram coletadas três amostras do escoamento para cada vazão ensaiada, no mesmo sulco. Os demais procedimentos foram iguais aos citados no tocante a entressulcos.

\section{Cálculo dos parâmetros da erosão hídrica em entres- sulcos}

A erodibilidade nos entressulcos foi calculada pela equação Di = Ki i ${ }^{2} \mathrm{Si}$ (Foster, 1982), em que: Di é a taxa de desagregação nos entressulcos $\left(\mathrm{kg} \mathrm{m}^{-2} \mathrm{~s}^{-1}\right) ; \mathrm{Ki}$, a erodibilidade nos entressulcos $\left(\mathrm{kg} \mathrm{s} \mathrm{m}^{-4}\right)$; $\mathrm{i}$, a intensidade da chuva $\left(\mathrm{m} \mathrm{s}^{-1}\right)$, e $\mathrm{Si}$, o fator de declividade. Esse fator é dado pela equação $\mathrm{Si}=1,05-0,85 \mathrm{e}^{-4 \operatorname{sen} \theta}$ (Liebenow et al., 1990), em que: e é a base do logaritmo natural, e $\theta$ é o ângulo do declive.

As perdas de solo (Ps) e de água (Pa) e a concentração de sedimentos $(\mathrm{C})$ foram determinadas nas amostras do escoamento coletadas no campo e pesadas em laboratório. Para determinar a perda total acumulada de água (Pta), dividiu-se o volume de cada coleta pelo tempo de coleta, multiplicouse pelo intervalo de tempo entre coletas consecutivas (5 minutos), e somou-se cumulativamente. Quanto à perda total acumulada de solo (Pts), procedeu-se da mesma maneira, usando-se a massa de solo perdida e coletada.

A taxa de escoamento (R) foi calculada dividindo-se o volume de água escoado pela área da parcela, multiplicado pelo tempo de coleta. A taxa de erosão (qs) foi encontrada dividindo-se a perda de solo pela área da parcela, multiplicando-se pelo tempo de coleta. Subtraindo a taxa de escoamento da água da lâmina precipitada, encontrou-se a taxa de infiltração (i).

\section{Cálculos dos parâmetros de erosão em sulcos}

A taxa de desagregação Dr foi calculada pela relação taxa de erosão/área total do sulco. A descarga sólida (qs) foi determinada pela equação: qs $=\mathrm{Q}$ Cs, onde: $\mathrm{Q}$ é a descarga líquida $\left(\mathrm{m}^{3} \mathrm{~s}^{-1}\right)$, e Cs é a concentração de sedimento $\left(\mathrm{kg} \mathrm{m}^{-3}\right)$, sendo que: $\mathrm{Q}=$ massa de água/tempo, e $\mathrm{Cs}=$ massa de solo/massa de água 
A área da seção transversal do escoamento (A) foi calculada por $\mathrm{A}=\mathrm{Q} / \mathrm{V}$ em que: $\mathrm{Q}$ é a descarga líquida, e $\mathrm{V}$, a velocidade média do escoamento. A velocidade média do escoamento (V) foi obtida pela multiplicação da velocidade da superfície do escoamento, obtida com uma tinta traçadora, pelo fator 0,74 (King, 1992). O raio hidráulico $(\mathrm{Rh})$ foi calculado pela fórmula $\mathrm{Rh}=\mathrm{A} /$ perímetro molhado, onde: A é a área da seção transversal do escoamento. A profundidade do escoamento foi determinada no campo com o auxílio de uma régua, medindo-se a distância entre um ponto fixo (sarrafo fixado acima do canal) e a superfície do escoamento de água.

Os sedimentos coletados foram fracionados em diferentes tamanhos, conforme Braida \& Cassol (1996a), determinando-se graficamente o seu tamanho mediano $\left(\mathrm{D}_{50}\right)$. $\mathrm{O} \mathrm{D}_{50}$ é o tamanho no qual $50 \%$ em peso é mais fino (Julien, 1998).

A carga de sedimento $(\mathrm{G})$, dada em $\mathrm{kg} \mathrm{m}^{-1} \mathrm{~s}^{-1}$, foi calculada dividindo-se a descarga sólida $\left(\mathrm{kg} \mathrm{s}^{-1}\right)$ pela largura do escoamento (m), em cada descarga. A capacidade de transporte $(\mathrm{Tc})$ do escoamento foi estimada pela equação de Yalin (Julien, 1998).

O número de Reynolds (Re) foi obtido pela equação $\mathrm{Re}=\mathrm{V} \mathrm{Rh} / \mathrm{v}$; o número de Froude $(\mathrm{F})$, pela relação $\mathrm{F}=\mathrm{V} /(\mathrm{g} \mathrm{Rh})^{0,5}$; e o fator de perda de carga de DarcyWeisbach (f), pela expressão $\mathrm{f}=8 \mathrm{~g} \mathrm{~S} \mathrm{~h} /(\mathrm{V})^{2}$ (Chow, 1959), onde: $\mathrm{V}$ é a velocidade média do escoamento $\left(\mathrm{m} \mathrm{s}^{-1}\right) ; \mathrm{Rh}, \mathrm{o}$ raio hidráulico $(\mathrm{m}) ; \mathrm{v}$, a viscosidade cinemática da água $\left(\mathrm{m}^{2} \mathrm{~s}^{-1}\right) ; g$, a aceleração da gravidade $\left(\mathrm{m} \mathrm{s}^{-2}\right) ; \mathrm{S}$, a declividade do escoamento; $h$, a profundidade do escoamento.

A tensão de cisalhamento do escoamento $(\tau), \mathrm{em} \mathrm{N} \mathrm{m}^{-2}$, foi determinada pela expressão $\tau=\mathrm{Rh} \mathrm{S} \delta$, onde: $\mathrm{S}$ é a declividade do sulco $\left(\mathrm{m} \mathrm{m}^{-1}\right)$; $\delta$ é o peso específico da água $\left(\mathrm{N} \mathrm{m}^{-3}\right)$.

A erodibilidade nos sulcos $(\mathrm{Kr})$ e a tensão crítica de cisalhamento $(\tau \mathrm{c})$ foram calculadas pela equação $\operatorname{Dr}=\operatorname{Kr}(\tau-\tau c)$, onde: Dr é a taxa de desagregação do solo nos sulcos $\left(\mathrm{kg} \mathrm{m}^{-2} \mathrm{~s}^{-1}\right) ; \mathrm{Kr}$, a erodibilidade do solo nos sulcos $\left(\mathrm{kg} \mathrm{N}^{-1} \mathrm{~s}^{-1}\right)$; $\tau$, a tensão cisalhante do escoamento $\left(\mathrm{N} \mathrm{m}^{-2}\right) ; \tau \mathrm{c}$, a tensão crítica de cisalhamento do solo $\left(\mathrm{N} \mathrm{m}^{-2}\right)$.

A análise estatística constou da análise de variância, teste de comparação de médias (Tukey a 5\% de probabilidade) e análise de regressão, usando o pacote estatístico SAS (SAS Institute, 1988).

\section{Resultados e Discussão}

\section{Erosão em entressulcos}

Independentemente da forma da seção transversal da parcela, as taxas de escoamento (R) nos entressulcos durante a chuva tiveram um comportamento hiperbólico, tendendo a um valor constante (Figura 1), concordando com os resultados de Braida \& Cassol (1996b, 1999). Trabalhos de Braida \& Cassol (1996b) e Cassol \& Lima (1998) mostraram que as taxas de erosão seguiram um comportamento quadrático, com um valor máximo antes do final da chuva de 90 minutos, enquanto neste estudo as taxas tenderam a um valor máximo, e a estabilizaremse, no final da chuva. Portanto, para o cálculo da erodibilidade nos entressulcos, usaram-se os valores de taxa de desagregação quando a erosão estabilizou-se (Figura 1), conforme o método de Elliot et al. (1989).

A resistência do solo ao cisalhamento $(\tau \mathrm{s})$ no final da chuva foi menor na STT que na STR (Tabela 1), indicando que o solo na parcela com declividade lateral construída (STT) apresentava uma superfície possivelmente mais compacta e menos resistente à tensão de cisalhamento produzida pelo

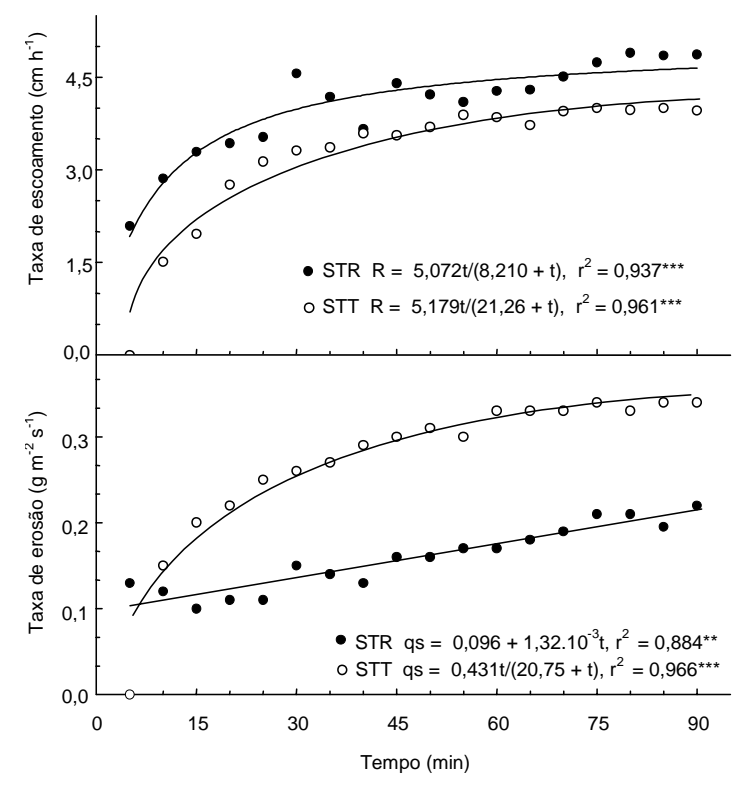

Figura 1. Taxa de escoamento (R) e de erosão (qs) nos entressulcos em função do tempo, em parcelas com seção transversal do sulco retangular (STR) e triangular (STT), em um Argissolo Vermelho-Amarelo distrófico arênico. $* *$ e $* * *$ Significativo a $1 \%$ e a $0,1 \%$ de probabilidade, respectivamente. 
impacto das gotas de chuva e pelo escoamento difuso. A menor resistência do solo na STT do que na STR esteve associada com menores taxas de escoamento, durante a chuva (R) e constante (Rc), e perda total de água (Pta), e com maiores descarga sólida durante a chuva (qs) e constante (qsc), perda total de solo (Pts) e concentração constante de sedimentos (Cc) (Tabela 1 e Figura 1). Liebenow et al. (1990) também observaram maior descarga sólida na parcela com sulco pré-formado (STT) em dezoito solos americanos, particularmente em solos mais erodíveis, como os arenosos.

O selamento superficial, indicado pela redução na infiltração de água no solo ou aumento no escoamento superficial, ocorreu em ambos os tipos de parcela. Solo preparado convencionalmente e sem cobertura é mais suscetível ao selamento superficial (Reichert et al., 1994; Barcelos et al., 1999; Braida \& Cassol, 1999). Com a desagregação do solo pelo impacto da chuva e a conseqüente obstrução dos poros na superfície do solo por compressão e migração de argilas, forma-se uma camada de baixa porosidade, que restringe a infiltração de água no solo (Reichert \& Norton, 1995).

Na parcela com declividade lateral construída (STT), a maior perda de solo por salpico e transporte

Tabela 1. Resistência do solo e parâmetros relacionados à erosão nos entressulcos em parcelas com seção transversal do sulco retangular e triangular, em um Argissolo Vermelho-Amarelo distrófico arênico.

\begin{tabular}{lcc}
\hline Variável $^{(1)}$ & \multicolumn{2}{c}{ Seção transversal } \\
\cline { 2 - 3 } & Retangular & Triangular \\
\hline$\tau \mathrm{s}\left(\mathrm{kN} \mathrm{m}^{-2}\right)$ & $2,17 \mathrm{a}$ & $1,50 \mathrm{~b}$ \\
$\mathrm{Di}\left(\mathrm{kg} \mathrm{m}^{-2} \mathrm{~s}^{-1}\right)$ & $2,09.10^{-4} \mathrm{a}$ & $3,35.10^{-4} \mathrm{a}$ \\
$\mathrm{Ki}\left(\mathrm{kg} \mathrm{s} \mathrm{m}^{-4}\right)$ & $1,77.10^{6} \mathrm{a}$ & $2,00.10^{6} \mathrm{a}$ \\
$\operatorname{Rc}\left(\mathrm{cm} \mathrm{h}^{-1}\right)$ & $4,66 \mathrm{a}$ & $3,98 \mathrm{~b}$ \\
$\mathrm{Pta}\left(\mathrm{cm}^{-1}\right.$ & $6,02 \mathrm{a}$ & $4,85 \mathrm{~b}$ \\
$\mathrm{ic}\left(\mathrm{cm} \mathrm{h}^{-1}\right)$ & $1,13 \mathrm{a}$ & $1,76 \mathrm{a}$ \\
$\mathrm{qsc}\left(\mathrm{g} \mathrm{m}^{-2} \mathrm{~h}^{-1}\right)$ & $752,50 \mathrm{~b}$ & $1.206,19 \mathrm{a}$ \\
$\mathrm{Pts}\left(\mathrm{g}^{-1}\right.$ & $286,20 \mathrm{~b}$ & $552,60 \mathrm{a}$ \\
$\mathrm{Cc}\left(\mathrm{g} \mathrm{L}^{-1}\right)$ & $11,81 \mathrm{~b}$ & $20,18 \mathrm{a}$ \\
\hline
\end{tabular}

${ }^{(1)} \tau$ S: resistência ao cisalhamento do solo; Di: taxa constante de desagregação; Ki: erodibilidade em entressulcos; Rc: taxa constante de escoamento; Pta: perda total de água; ic: taxa constante de infiltração; qsc: taxa constante de erosão; Pts: perda total de solo; Cc: concentração constante de sedimento. ${ }^{(2)}$ Médias seguidas pela mesma letra na linha não diferem pelo teste de Tukey a $5 \%$ de probabilidade. pelo escoamento raso no declive construído podem ter reduzido a formação de selo superficial, dado que as partículas finas foram transportadas para fora da parcela, mantendo maiores as taxas de infiltração de água no solo e menores as de escoamento superficial. Resultado e explicação semelhantes foram apresentados por Liebenow et al. (1990).

A erodibilidade nos entressulcos (Ki) foi estatisticamente similar nos dois formatos de parcela de erosão avaliados, STR e STT, embora o Ki fosse 1,12 vez maior na STT que na STR (Tabela 1). Liebenow et al. (1990) também não observaram diferença no Ki entre tipos de seção transversal, embora houvesse interação significativa entre formato de parcela e tipo de solo, indicando que o fator declividade do solo (Si) possivelmente necessite incluir algumas propriedades do solo para descrever adequadamente o processo erosivo em entressulcos.

Essa similaridade estatística permite usar parcelas de erosão nos entressulcos com seção transversal triangular ou retangular, para determinar a erodibilidade nos entressulcos (Ki). As diferenças de Ki obtidas por autores brasileiros podem ser atribuídas a diferenças intrínsecas dos solos estudados, como por exemplo, teores de argila e matéria orgânica. Nos solos com textura superficial francoarenosa, os resultados deste trabalho, à semelhança dos resultados de Rockenbach (1992), Braida \& Cassol (1996b) e Cassol \& Lima (1998), indicam que não houve diferenças de Ki entre a seção transversal retangular e a triangular.

$\mathrm{O}$ valor médio de $\mathrm{Ki}$, considerando as duas formas de seção transversal, foi $1,88.10^{6} \mathrm{~kg} \mathrm{~s} \mathrm{~m}^{-4}$. Este $\mathrm{Ki}$ está dentro dos limites de $\mathrm{Ki}\left(0,76.10^{6}\right.$ a $3,88.10^{6} \mathrm{~kg} \mathrm{~s} \mathrm{~m}^{-4}$ ) determinados por Elliot et al. (1989) em 36 solos dos Estados Unidos, mas é 2,71 vezes menor que aquele $\left(5,10.10^{-6} \mathrm{~kg} \mathrm{~s} \mathrm{~m}^{-4}\right)$ encontrado por Braida \& Cassol (1996b), o qual pode estar superestimado.

\section{Erosão em sulcos}

A taxa de desagregação nos sulcos (Dr) foi crescente e linear com o incremento da vazão $(Q)$ aplicada na STR (Figura 2). No entanto, nas duas últimas vazões na STT, essa taxa parece ter-se estabilizado, semelhantemente ao comportamento da tensão cisalhante $(\tau)$ do escoamento. 
A relação entre Dr e Q na STT parece indicar que o escoamento, nas últimas vazões, atingiu uma camada de solo menos erodível (Foster, 1982; Franti et al., 1985), o que diminuiu a concentração (C) (Figura 2), a carga (G), o tamanho mediano (Figura 3) e a capacidade de transporte (Tc) (Figura 3) de sedimentos. A relação G/Tc foi pequena (em média, 0,044 na STR e 0,065 na STT), o que indica que a taxa de desagregação (Dr) foi similar à capacidade de desagregação (Dc) do escoamento, uma vez que $\mathrm{Dr} / \mathrm{Dc}=1-(\mathrm{G} / \mathrm{Tc})$ (Foster, 1982), permitindo o uso da equação de erosão em sulco para o cálculo do $\mathrm{Kr}$ e $\tau$ c. Similarmente, King (1992) e Braida \& Cassol (1996b) observaram que a razão G/Tc foi pequena

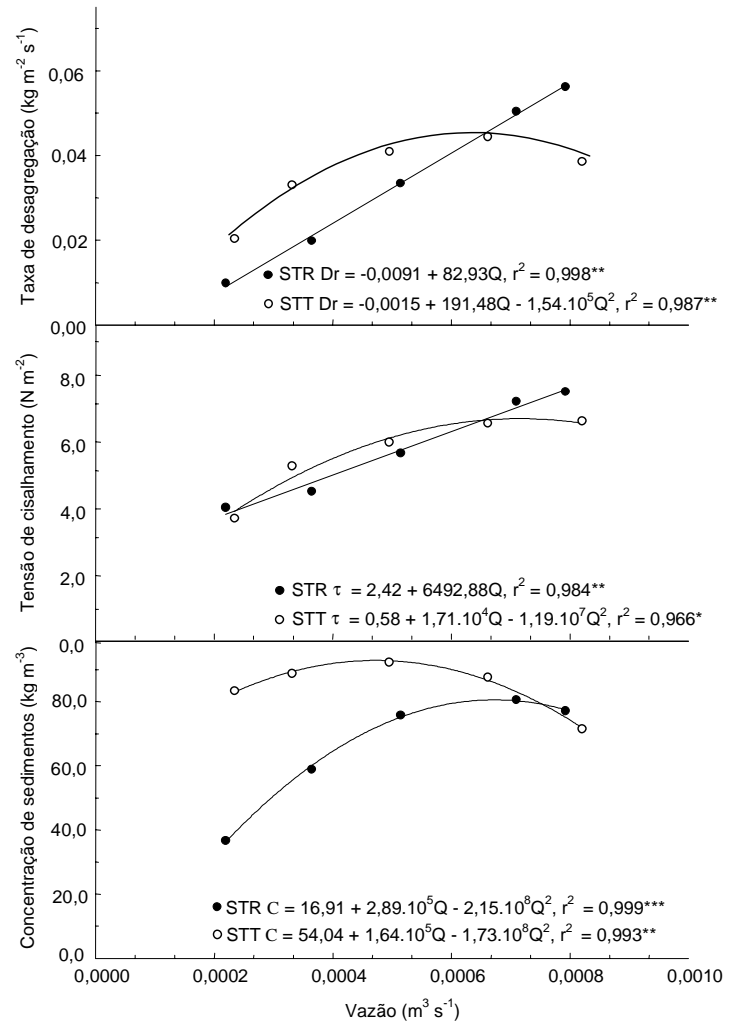

Figura 2. Taxa de desagregação (Dr), tensão de cisalhamento $(\tau)$ e concentração de sedimentos $(C)$ no escoamento em sulcos em função da vazão (Q), em parcelas com seção transversal do sulco retangular (STR) e triangular (STT), em um Argissolo Vermelho-Amarelo distrófico arênico. ${ }^{*}, *$ e $* * *$ Significativo a $5 \%$, a $1 \%$ e a $0,1 \%$ de probabilidade, respectivamente. para as vazões aplicadas aos sulcos, o que indica que o sedimento transportado afetou pouco a desagregação no sulco.

O tamanho, a forma e a resistência da rugosidade superficial contribuem no controle do movimento do fluxo superficial. O fator perda de carga de DarcyWeisbach (f) parece ser o melhor (Abrahams et al., 1986) entre os fatores de resistência normalmente usados. Uma curva relacionando o fator perda de carga (f) com o número de Reynolds (Re), relação $\mathrm{f}-\mathrm{Re}$, pode ser usada para predizer a resistência ao escoamento (Abrahams et al., 1994).

O regime do escoamento foi supercrítico $(\mathrm{F}>1)$ de transição (Re entre 500 e 2000) nas duas primeiras

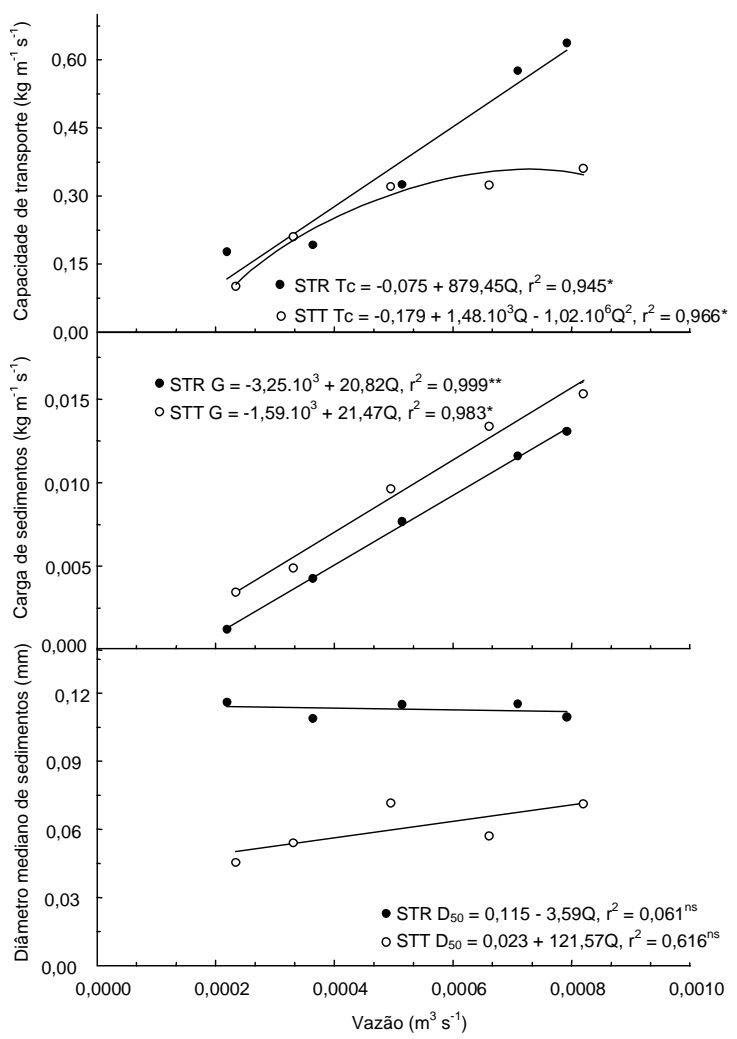

Figura 3. Capacidade de transporte (Tc), carga (G) e diâmetro mediano $\left(\mathrm{D}_{50}\right)$ de sedimentos no escoamento nos sulcos, em razão da vazão $(\mathrm{Q})$, em parcelas com seção transversal do sulco retangular (STR) e triangular (STT), em um Argissolo Vermelho-Amarelo distrófico arênico.

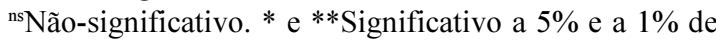
probabilidade, respectivamente. 
vazões, e posteriormente passou a ser supercrítico $(\mathrm{F}>1)$ turbulento (Re maior que 2000), nas duas seções transversais. O F praticamente não foi alterado pelo incremento na vazão nem pelo formato da parcela (Figura 4). Segundo Morgan (1995), com o aumento do Re há um incremento na capacidade de desagregação e transporte. No regime de escoamento supercrítico, as forças gravitacionais superam as inerciais e há formação de ondas (Chow, 1959), que aumenta a capacidade erosiva do escoamento (Morgan, 1995).

A turbulência do escoamento normalmente diminui a perda de carga (Chow, 1959), conforme obser-

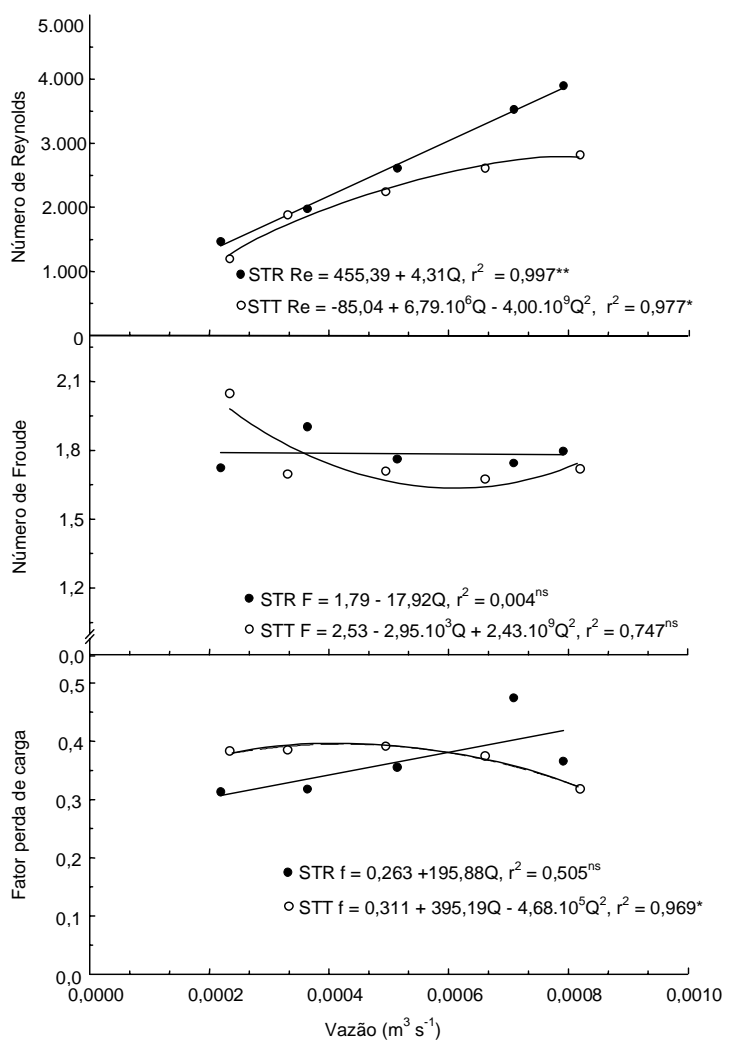

Figura 4. Números de Reynolds (Re) e de Froude (F) e fator perda de carga (f) do escoamento em sulcos em função da vazão $(Q)$, em parcelas com seção transversal do sulco retangular (STR) e triangular (STT), em um Argissolo

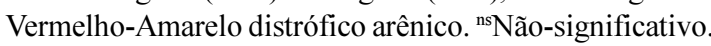
* e**Significativo a $5 \%$ e a $1 \%$ de probabilidade, respectivamente. vado na STT. Entretanto, na STR houve uma tendência de aumento na perda de carga com o incremento da turbulência (Figura 4), possivelmente devido ao aumento na rugosidade de forma resultante da incisão do sulco. Conforme Chow (1959), o tamanho, a forma e a resistência da rugosidade superficial contribuem no controle do escoamento superficial. O fator perda de carga de Darcy-Weisbach (f) parece ser o melhor (Abrahams et al., 1986) entre os fatores de resistência normalmente usados; esse fator descreve perdas de carga e de contato resultantes de forças de cisalhamento entre o fluído e a superfície do solo. Uma curva relacionando o fator perda de carga (f) com o número de Reynolds ( $R e$ ), relação f-Re, pode ser usada para predizer a resistência ao escoamento (Abrahams et al., 1994).

Embora o $\tau \mathrm{c}$ e o $\mathrm{Kr}$ fossem 1,31 e 1,49 vez menores na STR que na STT (Figura 5), respectivamente, tanto o $\mathrm{Kr}$ quanto o $\tau \mathrm{c}$ foram estatisticamente similares nas duas seções transversais, indicando, assim, que essas duas variáveis da erosão em sulcos podem ser determinadas em seção transversal ou em retangular, pelo menos em solo com textura superficial franco arenosa. A literatura não apresenta resultados de outros experimentos avaliando o efeito da seção transversal da parcela em sulcos.

Os valores médios, nas duas seções transversais avaliadas, de $\operatorname{Kr}\left(0,0092 \mathrm{~kg} \mathrm{~N}^{-1} \mathrm{~s}^{-1}\right)$ e $\tau \mathrm{c}\left(2,30 \mathrm{~N} \mathrm{~m}^{-2}\right)$. Esses valores encontram-se dentro dos limites de $\mathrm{Kr}$

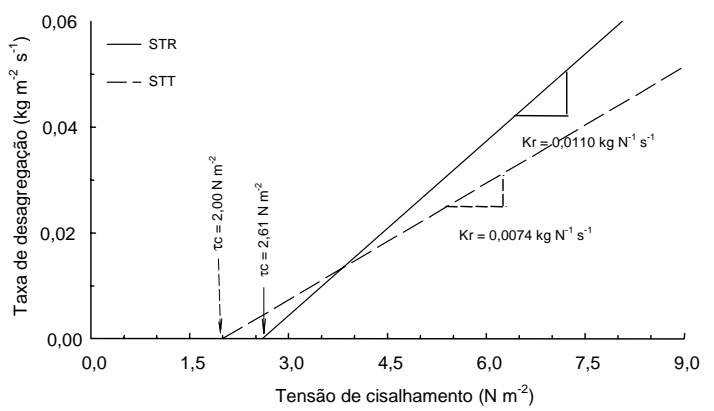

Figura 5. Relação entre taxa de desagregação (Dr) e tensão de cisalhamento $(\tau)$ nos sulcos, com indicação da erodibilidade nos sulcos $(\mathrm{Kr})$ e tensão crítica de cisalhamento $(\tau c)$, nas parcelas com seção transversal do sulco retangular (STR) e triangular (STT), em um Argissolo Vermelho-Amarelo distrófico arênico. 
de $0,6 \cdot 10^{-3}$ a $45,3 \cdot 10^{-3} \mathrm{~kg} \mathrm{~N}^{-1} \mathrm{~s}^{-1}$ e de $\tau$ c de 0,4 a $6,6 \mathrm{~N} \mathrm{~m}^{-2}$ encontrados por Elliot et al. (1989) para 36 solos dos Estados Unidos. Braida \& Cassol (1996b), para um solo da mesma unidade de mapeamento porém menos argiloso (140 $\left.\mathrm{g} \mathrm{kg}^{-1}\right)$ de argila, em seção transversal triangular, obtiveram um $\mathrm{Kr}$ $\left(0,0104 \mathrm{~kg} \mathrm{~N}^{-1} \mathrm{~s}^{-1}\right)$ e $\tau \mathrm{c}\left(4,81 \mathrm{~N} \mathrm{~m}^{-2}\right)$ maior ao deste estudo.

O uso de bordaduras metálicas para confinar o escoamento mostrou-se adequado para o estudo da erosão em sulcos. As lâminas usadas para borda são rígidas e com um bisel cortante, permitindo o corte de resíduos e do solo, praticamente não perturbando a superfície do solo. Em solo preparado, eventuais espaços entre o solo e borda podem ser preenchidos e compactados manualmente. Não houve erosão preferencial ao longo da borda metálica. Esse método evita a pré-formação de sulcos (Foster et al., 1982; Giasson \& Cassol, 1996), permitindo o estudo da erosão em sulcos sob sistemas de plantio direto (King, 1992). Sulcos com bordas metálicas têm sido usados por Franti et al. (1985), para conter o fluxo em sulcos onde necessário, e por King (1992), para estudos de erosão em solo com plantio direto, quando o tratamento não era o preparo em camalhões ("ridge-tillage").

\section{Conclusão}

Em Argissolo Vermelho-Amarelo com textura superficial franco arenosa, os parâmetros erodibilidade nos entressulcos e nos sulcos e a tensão crítica de cisalhamento do solo podem ser determinados tanto em parcelas de erosão com seção transversal retangular como triangular, produzindo valores similares.

\section{Agradecimentos}

Aos bolsistas de iniciação científica Márcio José Silveira, Celso Gonçalves, Emerson Wohlemberg e Márcio Conceição, pelo auxílio nos trabalhos de campo e de laboratório.

\section{Referências}

ABRAHAMS, A. D.; PARSON, A. J.; LUK, S. H. Resistance to overland flow on desert hillslopes. Journal of Hydrology, Amsterdam, v. 88, p. 343-363, 1986.
ABRAHAMS, A. D.; PARSONS, A. J.; WAINWRIGHT, J. Resistance to overland flow on semiarid grassland and shrubland hillslopes, Walnut Gulch, southern Arizona. Journal of Hydrology, Amsterdam, v. 156, p. 431-446, 1994.

BARCELOS, A. A.; CASSOL, E. A.; DENARDIN, J. E. Infiltração de água em um Latossolo Vermelho-Escuro sob condições de chuva intensa em diferentes sistemas de manejo. Revista Brasileira de Ciência do Solo, Campinas, v. 23, p. 35-43, 1999.

BRAIDA, J. A.; CASSOL, E. A. Distribuição do tamanho de partículas do sedimento determinada a campo e em laboratório. Revista Pesquisa Agropecuária Gaúcha, Porto Alegre, v. 2, p. 93-99, 1996a.

BRAIDA, J. A.; CASSOL, E. A. Erodibilidade em sulcos e em entressulcos em um Podzólico Vermelho-Escuro franco-arenoso. Revista Brasileira de Ciência do Solo, Campinas, v. 20, p. 127-134, 1996b.

BRAIDA, J. A.; CASSOL, E. A. Relações da erosão em entressulcos com o tipo e a quantidade de resíduo vegetal na superfície do solo. Revista Brasileira de Ciência do Solo, Campinas, v. 23, p. 711-721, 1999.

BROWN, L. C.; NORTON, L. D. Surface residue effects on soil erosion from ridges of different soils and formation. Transactions of the ASAE, St. Joseph, v. 37, p. 15151524, 1994.

CASSOL, E. A.; LIMA, V. S. de. Erosão em entressulcos em um Podzólico Vermelho-Amarelo do Rio Grande do Sul sob diferentes preparos do solo e manejo de resíduos culturais. In: REUNIÃO BRASILEIRA DE MANEJO E CONSERVAÇÃO DO SOLO E DA ÁGUA, 12., 1998 , Fortaleza. Anais... Fortaleza : Sociedade Brasileira de Ciência do Solo/UFC, 1998. p. 354-355.

CHOW, V. T. Open-channel hydraulics. New York : McGraw-Hill, 1959. 680 p.

ELLIOT, W. J.; LIEBENOW, A. M.; LAFLEN, J. M.; KOHL, K. D. A compendium of soil erodibility data from WEPP cropland soil field erodibility experiments 1987/88. West Lafayette : The Ohio State University/ USDA-Agricultural Research Service, 1989. p. A2-A25. (NSERL Report, 3).

EMBRAPA. Centro Nacional de Pesquisa de Solos (Rio de Janeiro, RJ). Sistema brasileiro de classificação de solos. Brasília : Embrapa-SPI, 1999. 412 p.

FOSTER, G. R. Modeling the erosion process. In: HANN, C. T.; JOHSON, H. P.; BRAKENSIEK, D. L. (Ed.). 
Hydrologic modeling of small watersheds. St. Joseph : American Society of Agricultural Engineering, 1982. p. 297 380.

FRANTI, T. G.; LAFLEN, J. M.; WATSON, D. A. Soil erodibility and critical shear under concentrated flow. St. Joseph : American Society of Agricultural Engineering, 1985. (ASAE Paper, 85-2033)

GIASSON, E.; CASSOL, E. A. Relações da erosão em sulcos com vazões aplicadas e doses de resíduos de trigo incorporados a um Plintossolo franco-argilo arenoso. Revista Brasileira de Ciência do Solo, Campinas, v. 20, p. 117-125, 1996.

HOLTZ, R. D.; KOVACS, W. D. An introduction to geotechnical engineering. Englewood Cliffs : Prentice Hall, 1981. $733 \mathrm{p}$

JULIEN, P. Y. Erosion and sedimentation. New York Cambridge University Press, 1998. 280 p.

KING, K. W. Comparison of rill erodibility parameters as influenced by no-till farming. West Lafayette : Purdue University, 1992. 98 p. M.Sc. Dissertation.

LIEBENOW, A. M.; ELLIOT, W. J.; LAFLEN, J. M.; KOHL, K. O. Interrill erodibility: collection and analysis of data from cropland soils. Transactions of the ASAE, St. Joseph, v. 33, p. 1882-1888, 1990.
MORGAN, R. P. C. Soil erosion \& conservation. 2. ed New York : Longman, 1995. 198 p.

NORTON, L. D; BROWN, L. C. Time-effect on water erosion for ridge tillage. Transactions of the ASAE, St. Joseph, v. 35, p. 473-478, 1992.

REICHERT, J. M.; NORTON, L. D. Surface seal micromorphology as affected by fluidized bed combustion bottom-ash. Soil Technology, Amsterdam, v. 7, p. 303317,1995

REICHERT, J. M.; NORTON, L. D.; HUANG, C. Sealing, amendment, and rain intensity effects on erosion of highclay soils. Soil Science Society of America Journal, Madison, v. 58, p. 1199-1205, 1994.

ROCKENBACH, C. A. Erosão em entressulcos sob diferentes coberturas por resíduos de trigo em um solo Podzólico Vermelho-Amarelo sob chuva simulada. Porto Alegre : UFRGS, 1992. 108 p. Dissertação de Mestrado.

SAS Institute (Cary, Estados Unidos). SAS/STAT users guide: version 6.03. Cary, 1988. $1028 \mathrm{p}$.

WEST, L. T.; MILLER, W. P.; LANGDALE, R. R.; BRUCE, R. R.; LAFLEN, J. M.; THOMAS, A. W. Cropping system and consolidation effects on rill erosion in the Georgia Piedmont. Soil Science Society of America Journal, Madison, v. 56, p. 1238-1243, 1992. 